\title{
Paternal Biological Grandparent
}

National Cancer Institute

\section{Source}

National Cancer Institute. Paternal Biological Grandparent. NCI Thesaurus. Code C111286.

A relative who is the biological parent of the biological father. 